\title{
Growth of Boron Nitride Nanotubes Having Large Surface Area Using Mechanothermal Process
}

\author{
Sunil K. Singhal ${ }^{1}$, Avanish K. Srivastava ${ }^{2}$, Rakesh B. Mathur ${ }^{1}$ \\ ${ }^{1}$ Physics \& Engineering of Carbon, National Physical Laboratory, Council of Scientific \& Industrial \\ Research, New Delhi, India \\ ${ }^{2}$ Ion \& Electron Microscopy, National Physical Laboratory, Council of Scientific \& Industrial \\ Research, New Delhi, India \\ E-mail: sksinghal@mail.nplindia.ernet.in \\ Received September 22, 2011; revised October 5, 2011; accepted October 29, 2011
}

\begin{abstract}
Nanostructures of boron nitride $(\mathrm{BN})$ including nanotubes, nanofibers and nanosheets having a large surface area are very useful in storing hydrogen and other gases. In the present paper we report the synthesis and characterization of these nanostructures of $\mathrm{BN}$ using mechanothermal process. Under this process elemental boron powder is first ball milled to about $50 \mathrm{~h}$ in an inert atmosphere and then annealed at $1100^{\circ} \mathrm{C}-1250^{\circ} \mathrm{C}$ for $6 \mathrm{~h}$ in the presence of $\mathrm{NH}_{3}$ gas. By this treatment nanotubes and other nanostructures of $\mathrm{BN}$ were synthesized. The diameter of BN nanotubes varied from 20 to $50 \mathrm{~nm}$ and most of them exhibited spindle or bamboo like morphology. Because of the large surface area, these nanotubes may be explored for a better hydrogen gas storage device as compared to the crystallized nanotubes. The main advantage of this technique is that the nanotubes can be grown in large quantity. A possible growth mechanism towards the evolution of such fascinating nano-objects of boron nitride has been discussed employing high-resolution transmission electron microscopy and photoluminescence.
\end{abstract}

Keywords: Boron Nitride Nanotubes, Mechanothermal Process, Morphology, Photo Luminescence

\section{Introduction}

Boron nitride $(\mathrm{BN})$ nanotubes have received considerable attention in the recent years due to their outstanding properties such as an electrical insulator with a band gap of $5.9 \mathrm{eV}$ [1], resistance to oxidation at high temperature (above $800^{\circ} \mathrm{C}$ ) [2] and excellent thermal conductivity [3]. Recently the use of BN nanotubes in the fabrication of polymer based composites for photovoltaic packaging [4] and in the reinforcement of glass to be used as a sealing material in a solid oxide fuel cell [5] is being reported. However, as the synthesis of nanostructure materials matures, there is a growing interest to study the hydrogen storage of new nanostructure materials. Nanostructure materials are one of most promising classes of advanced materials for hydrogen $\left(\mathrm{H}_{2}\right)$ storage owing to their unique chemical, physical, thermodynamic and transport properties as compared to their bulk forms. In this class, carbon nanotubes (CNTs) and nanofibers (NF) are being considered as promising candidates for $\mathrm{H}_{2}$ storage because of their fine powdered morphology and highly porous structure. However, the hydrogen storage capacity of boron nitride nanostructures is found to be better than CNTs. The $\mathrm{H}_{2}$ storage capacity of pure multi walled CNTs at room temperature (RT) was measured to be < $0.01 \mathrm{wt} \%$ [6] and for single walled CNTs bundles $\sim 0.6$ $\mathrm{wt} \%$ under $10 \mathrm{MPa}$ at RT [7].

It has been found that the nanostructures of $\mathrm{BN}$, namely boron nitride nanotubes, exhibit reproducible hydrogen uptake of $1.8-2.2 \mathrm{wt} \%$ at $6 \mathrm{MPa}[8]$ and nanofibers could absorb $2.9 \mathrm{wt} \%$ under $10 \mathrm{MPa}$ at RT [9]. Theoretical calculations by Zhou et al [10] have shown that a well-crystallized, perfect boron nitride nanotubes is infect not a good candidate for $\mathrm{H}_{2}$ storage because of either physical or chemical absorption mechanisms. Therefore, novel nanostructures in BN have been found to be of prime importance, and an increase in surface area for these nanostructure materials may result in an increased $\mathrm{H}_{2}$ storage capacity. Among the various nanostructures of $\mathrm{BN}$, collapsed or surface-modified boron nitride nanotubes are found to have superb $\mathrm{H}_{2}$ storage capacity [11] due to their highest surface area of these materials. A 
collapsed boron nitride nanotube consists of numerous curved BN fragments, has a large surface area and contains numerous dangling bonds and may favor the adsorption of $\mathrm{H}_{2}$.

Thus, although, BN nanotubes are synthesized using a number of methods including arc-discharge [12], laser ablation [13], carbon substitution reactions [14], chemical vapor deposition [15] and ball milling and anneal- ing methods [16-23], the $\mathrm{BN}$ nanotubes produced in these methods were mostly smooth surface having bamboo-like or cylindrical morphology and therefore, may have lower surface area. In this direction, very recently Terao et al [24] have reported a carbon free CVD process for the synthesis of surface modified BN nanostructures, however, the yield of these nanostructures was not very high and it is suggested that the addition of some metal oxide may improve the yield of these nanostructures [25]. In the present study we report the synthesis of nanostructures of BN (nanotubes, nanosheets and nanofibers) having large surface area by mechanically milled boron powder in the presence of ammonia gas followed by annealing at a very controlled rate. This process has an advantage over the other methods reported earlier as one can synthesize these nanostructures in a large quantity. A possible growth mechanism for the growth of these nanostructures is also described.

\section{Experimental Details}

The starting material used in the present investigation was B powder supplied by Sigma Aldrich having a purity of about $95 \%-97 \%$. It contained a small amount of $O$ $(1.7 \%)$ and $\mathrm{Mg}(0.5 \%)$ as impurities and its average particle size was reported to be $900 \mathrm{~nm}$. The high-energy ball milling (HEBM) experiments were carried out in a Planetary Ball mill (M/s Insmart Systems, Hyderabad, India), in which four stainless steel containers of size 250 $\mathrm{ml}$ or $500 \mathrm{ml}$ can be used. In the present investigation, two containers of $250 \mathrm{ml}$ were used. A small quantity (7 g) of elemental B powder was loaded in each cell containing 40 Nos. of hardened steel balls of diameter 12 $\mathrm{mm}$. The stainless containers were filled with ammonia gas at a pressure of $300 \mathrm{KPa}$ and closed tightly. Although we have not studied the effect of gas pressure on milling, we believe that at milling is very effective at high pressure environment of the cell and also it reduces the milling time. The balls to powder weight ratio was 40:1. The erosion of steel balls during ball milling provides sufficient $\mathrm{Fe}$ nanoparticles that may acts as catalyst for the nucleation of BN nanotubes during subsequent annealing. The powders were milled at a speed of $500 \mathrm{rpm}$ and the milling time was varied from 10 to $50 \mathrm{~h}$. A small quantity $(70 \mathrm{mg}$ ) of the milled powder was taken out after an interval of $10 \mathrm{~h}$ and characterized by X-ray diffraction (XRD) in order to observe the degree of amorphization, particle size reduction and metal contamination. High-resolution transmission electron microscopy (HRTEM) was performed to study the growth pattern, lattice scale features and a qualitative evolution of $\mathrm{BN}$ nanotubes having large surface area. The X-ray characterization of the BN nanostructures was carried out by means of Rigaku D/MAX2400 X-ray diffraction analysis (Rigaku Corp. Tokyo, Japan) using $\mathrm{CuK} \alpha$ radiation $(\lambda=0.15418 \mathrm{~nm})$ at room temperature. The morphology of the nanoparticles and nanotubes was observed by a scanning electron microscope (SEM, model LEO 440) and a high resolution transmission electron microscope (HRTEM, model FEI Tecnai $\mathrm{G}^{2}$ F30 STWIN with FEG source at the electron acceleration voltage of $300 \mathrm{kV}$ ).

Annealing experiments were carried out in a horizontal tubular furnace. For annealing experiments, B powder milled for $40 \mathrm{~h}-50 \mathrm{~h}$ was used. The annealing was carried out at the optimized conditions namely $1100^{\circ} \mathrm{C}$ $1300^{\circ} \mathrm{C}$ in nitrogen/ammonia atmosphere for $6 \mathrm{~h}$ as reported by Chen et al. [17]. The milled samples were taken in an alumina boat and placed at the center of the quartz tube and heated first in Ar atmosphere at the heating rate of about $15^{\circ} \mathrm{C} / \mathrm{min}$ up to $1300^{\circ} \mathrm{C}$. When the desired annealing temperature $\left(1100^{\circ} \mathrm{C}-1300^{\circ} \mathrm{C}\right)$ was achieved, $\mathrm{Ar}$ was replaced by $\mathrm{NH}_{3}$ and the reaction was carried out for about $6 \mathrm{~h}$. After the reaction was over, the sample was cooled to room temperature in $\mathrm{NH}_{3}$ atmosphere slowly $\left(10^{\circ} \mathrm{C} / \mathrm{min}\right)$.

\section{Results and Discussion}

\subsection{Phase Formation and Chemistry of the Materials at Different Milling Conditions}

Figure 1(a) shows an X-ray diffraction pattern of the starting $B$ powder used in the present work. This powder was found to be highly crystalline and all peaks of $\mathrm{B}$ powder were indexed with "d" values of 5.0610 A, 4.84546 A, 4.67290 A and 4.41290 A etc.

Figures 1(b)-(e) shows XRD patterns of B powders milled for 10, 20, 30 and $50 \mathrm{~h}$ respectively. From Figure 1(b) it was seen that although all major peaks of elemental B powder were indexed as mentioned above, the peak height or intensities of all peaks observed in Figure 1(a) decreased to about $30 \%$ indicating the partial transformation of crystalline to disordered structure. However, a sharp change in the crystallinity was observed in the XRD patterns of B powder milled for 20 and $30 \mathrm{~h}$ respectively as shown in Figures 1(c) and (d). The $20 \mathrm{~h}$ milled sample still showed partly conversion from crystalline to amorphous phase of elemental B powder. The 
intensity of almost all XRD peaks of B decreased sharply. However, one broad peak appeared at around $2 \theta=44^{\circ}$ with a "d" value of 2.0769 A. This peak was indexed to be due to $\alpha-\mathrm{Fe}$, mixed in the milled powder as a small contamination mainly due to the abrasion from the surface of stainless steel container and hardened steel balls during high-energy ball milling. An XRD pattern of a 30 $\mathrm{h}$ milled B powder shown in Figure 1(d) indicated an almost complete amorphization of B powder as no peak due to elemental B could be indexed in this XRD pattern. Again in this XRD pattern also an XRD peak appeared at around $2 \theta=44^{\circ}$ indicating the contamination of Fe nanoparticles also observed in a $20 \mathrm{~h}$ milled sample. Figure 1(e) shows an XRD pattern of B powder milled for $50 \mathrm{~h}$. This pattern shows complete amorphization of $\mathrm{B}$.

Although the quantitative measurement of $\mathrm{N}$ and $\mathrm{Fe}$ concentration in the milled $\mathrm{B}$ powders could not be done because of the presence of $\mathrm{O}$ present in the starting $\mathrm{B}$ powder, we could get some qualitative information about these elements present in the milled powder using EDS analysis. Absorption of oxygen could not be avoided because of large surface area of the milled powder. A comparative qualitative analysis showed that the nitridetion of B powder was higher in a $30 \mathrm{~h}$ milled powder as compared to the nitridation observed in a $20 \mathrm{~h}$ milled B powder.

Figures 2(a) and (b) show EDS (attached with SEM) patterns of B powders milled for $20 \mathrm{~h}$ and $30 \mathrm{~h}$ respecttively. From these patterns it is clear that the concentration of $\mathrm{N}$ in a $30 \mathrm{~h}$ milled sample was relatively higher to that observed in a $20 \mathrm{~h}$ milled sample. It is also clear from these two patterns that the density of $\mathrm{Fe}$ contamination also increased when the milling time was increased from $20 \mathrm{~h}$ to $30 \mathrm{~h}$. These results are in agreement with the results obtained by Chen et al. [16-19]. As already pointed out these nitridation reactions also results in the formation of nanosized $\mathrm{BN}$ phases which may serve as

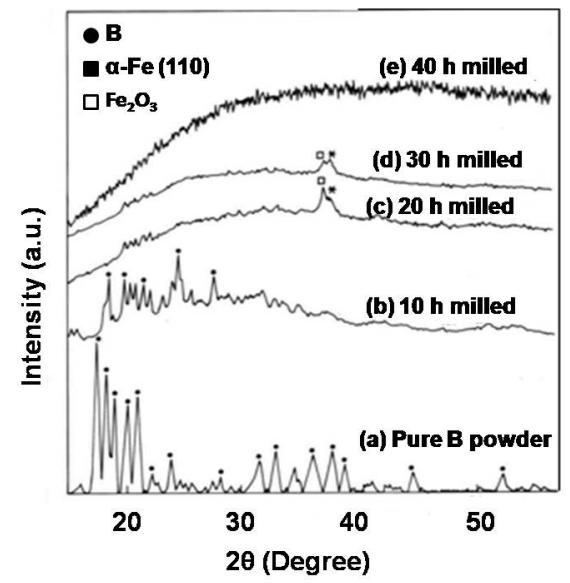

Figure 1. XRD pattern of B powder; (a) Pure and milled for; (b) $10 \mathrm{~h}$; (c) $20 \mathrm{~h}$; (d) $30 \mathrm{~h}$; and (e) $40 \mathrm{~h}$ respectively.

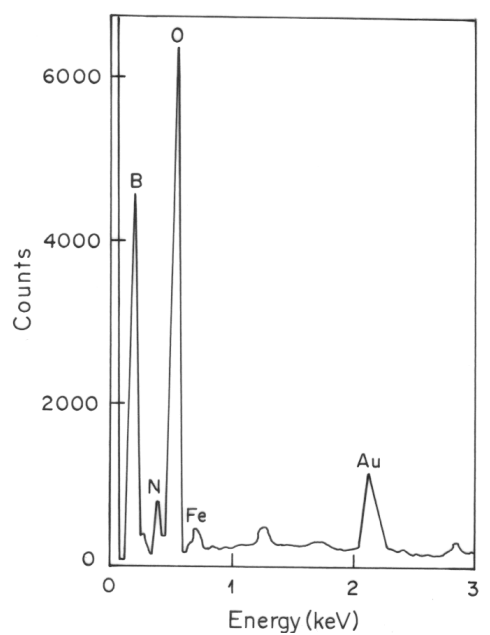

(a)

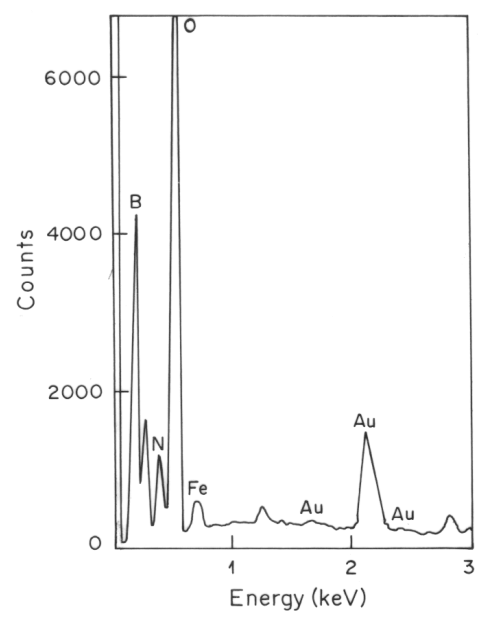

(b)

Figure 2. EDS spectrum of B powders milled for (a) 20 h and (b) $30 \mathrm{~h}$.

nuclei for the growth of $\mathrm{BN}$ nanotubes during the subsequent annealing. As the milled powder produced after 40 - $50 \mathrm{~h}$ was completely amorphous, this powder was used to study the growth of BN nanotubes during the subsequent annealing.

Figures 3(a)-(c) shows XRD patterns of BN nanotubes synthesized from $50 \mathrm{~h}$ milled $\mathrm{B}$ powder followed by annealing at $1100^{\circ} \mathrm{C}-1250^{\circ} \mathrm{C}$ under $\mathrm{NH}_{3}$ gas for $6 \mathrm{~h}$.

Figure 4 represents a XRD pattern of BN nanotubes grown from $50 \mathrm{~h}$ milled $\mathrm{B}$ powder after annealing at $1300^{\circ} \mathrm{C}$. From Figures $\mathbf{3}$ and $\mathbf{4}$ it is clear that although B samples milled for 40 and $50 \mathrm{~h}$ were completely amorphized, the yield of $\mathrm{BN}$ nanotubes obtained at $1250^{\circ} \mathrm{C}$ was relatively higher than that obtained at $1300^{\circ} \mathrm{C}$, as evidenced by the peak height of (002) reflection of hBN. From these results it is observed that the annealing temperature has a pronounced effect on the yield of $\mathrm{BN}$ nanotubes. The yield is lower at higher annealing tem- 
perature $\left(1300^{\circ} \mathrm{C}\right.$ and higher). The growth of $\mathrm{BN}$ nanotubes is presumed to takes place via the dissolution of nanosized $\mathrm{B} / \mathrm{BN}$ species in the catalyst nanoparticles of Fe. The catalyst (Fe-nanoparticles) should be in a quasiliquid state in order to dissolve maximum concentration of $\mathrm{B} / \mathrm{BN}$ phased to a state of supersaturation. $\mathrm{BN}$ nanotubes are grown from the supersaturated solution layer by layer along the (002) planes. It was also found by $\mathrm{Yu}$ et al. [26] that a much higher annealing temperature ( $\mathrm{T}>$ $1300^{\circ} \mathrm{C}$ ) is not favored for the growth of $\mathrm{BN}$ nanotubes as at this temperature, the catalyst nanoparticles (Fe) would be in the liquid state and they may merged together to form large size Fe crystals and then may impede the growth of $\mathrm{BN}$ nanotubes. Also the $\mathrm{B}$ particles may react directly with $\mathrm{N}$ to form $\mathrm{BN}$ particles instead of nanotubes and used up the B source.

At temperatures lower than $1100^{\circ} \mathrm{C}$, the low diffusion rate of $\mathrm{B}$ and $\mathrm{N}$ in $\mathrm{Fe}$ would slow down the precipitation rate of $\mathrm{BN}$ layers (i.e. the growth rate of $\mathrm{BN}$ nanotubes). Figure 5 shows an XRD pattern of the products produced from un-milled $\mathrm{B}$ powder and annealed at $1300^{\circ} \mathrm{C}$ in the presence of ammonia gas. No BN nanotube growth was found from this powder under the same annealing conditions that produced nanotubes from the milled samples. This suggests that the milling process has an essential role to play in $\mathrm{BN}$ nanotube formation during subsequent annealing, which appears to be associated with the creation of suitable nucleation sites for nanotube growth. Under the high milling intensity used in the present work, elemental B was transformed into disordered amorphous phase. The amorphous phase is metastable and recrystallized during the annealing process.

It has been observed that $\mathrm{Fe}$ and other metal nanopar- ticles (Cr, Ni etc.) were introduced into the milled B powder during ball milling from the surface of stainless steel balls and container. The milling contamination is almost unavoidable by the mechanical milling process, especially under high milling intensity, and this contamination increases with milling time as observed by the increase in peak intensity of Fe shown in XRD patterns of the milled B powders. In general, such milling contamination is undesirable but, in the present case $(\mathrm{Fe}, \mathrm{Ni}$, $\mathrm{Cr}$ from the stainless steel container) have been found to have positive catalytic role in promoting $\mathrm{BN}$ nanotube

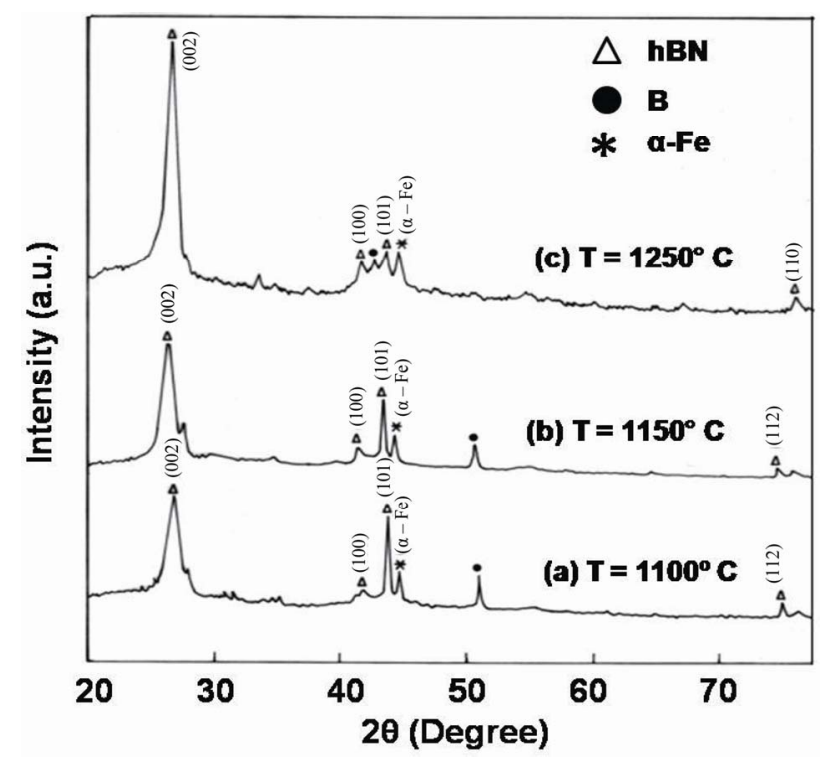

Figure 3. XRD patterns of $B N$ nanotubes synthesized from $B$ powder milled for $50 \mathrm{~h}$ and annealed at (a) $1100^{\circ} \mathrm{C}$; (b) $1150^{\circ} \mathrm{C}$ and (c) $1250^{\circ} \mathrm{C}$ under $\mathrm{NH}_{3}$ gas for $6 \mathrm{~h}$.

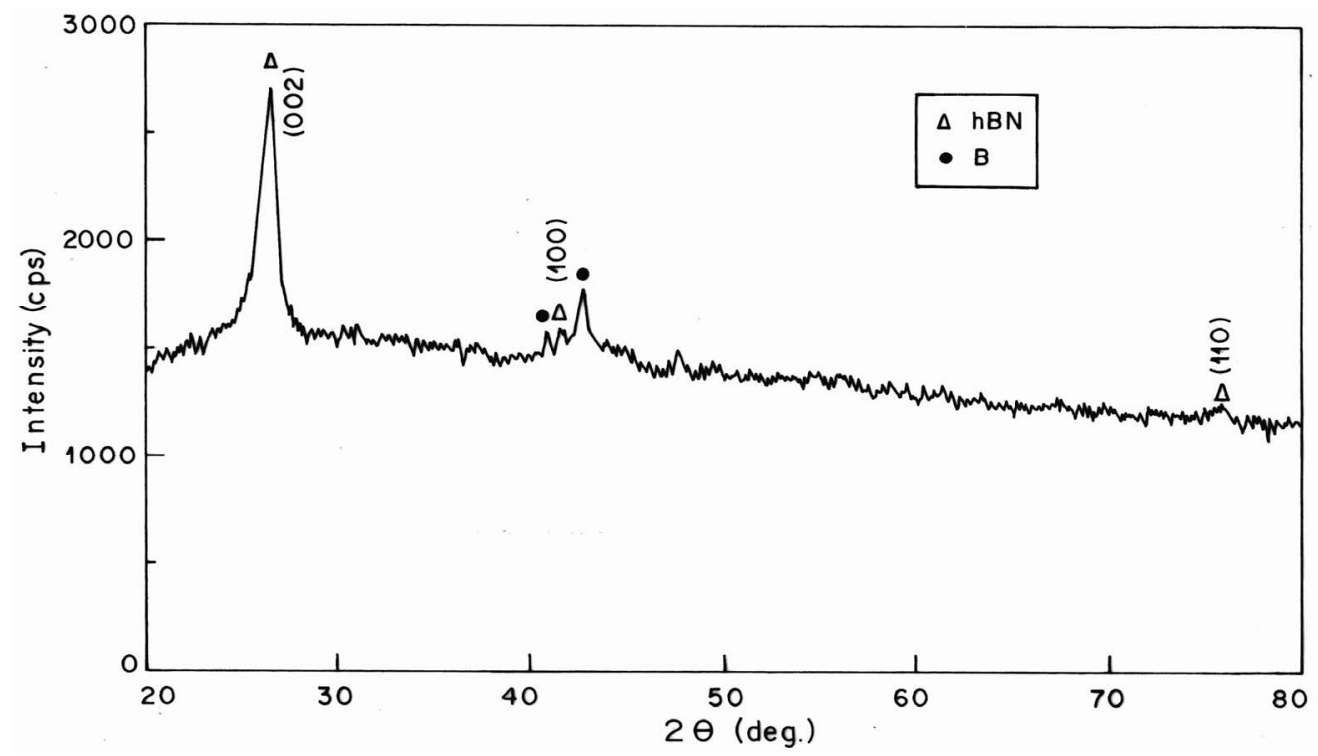

Figure 4. XRD pattern pf $\mathrm{BN}$ nanotubes synthesized at $1300^{\circ} \mathrm{C}$. 


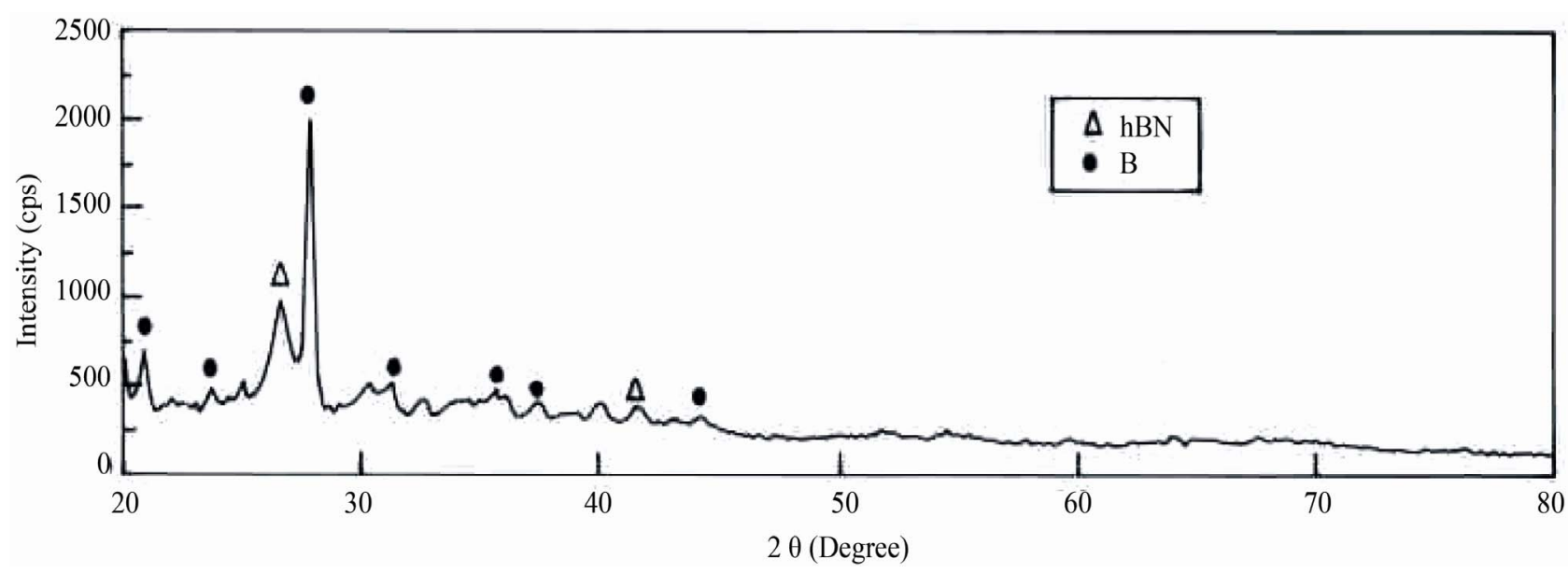

Figure 5. XRD pattern of the products produced from un-milled B powder.

formation. Actually, a high yield of $\mathrm{BN}$ nanotubes is reported to be formed above a certain level of metal content $(1 \mathrm{wt} \%)$. Such catalytic effects have been reported extensively in the literature for nanotube formation by other methods [27].

The XRD results shown in Figures 3 and $\mathbf{4}$ have revealed that the amorphous phase of $\mathrm{B}$ recrystallizes to form dominant (002) phases during annealing process. As the growth of BN nanotubes was observed in the temperature range of about $1100^{\circ} \mathrm{C}-1300^{\circ} \mathrm{C}$, which is much below the boiling point of $\mathrm{B}\left(2550^{\circ} \mathrm{C}\right)$ and sublimation temperature of $\mathrm{BN}\left(3000^{\circ} \mathrm{C}\right)$, we speculate that the vapor phases of $\mathrm{B}$ or $\mathrm{BN}$ are not possible during $\mathrm{BN}$ nanotube growth under the experimental conditions used.

In the present case, it is expected that the nucleation and growth of $\mathrm{BN}$ nanotube takes place in the solid state, and during the annealing conditions surface diffusion is the most likely mechanism for nanotube growth as observed by Chadderton and Chen [28], although in our opinion solid-liquid-solid (SLS) mechanism is also expected to be operative in the present case. It is likely that some of the milled $\mathrm{B} / \mathrm{BN}$ phases dissolve in nanoscale $\mathrm{Fe}$ particles to a state of super saturation during the annealing conditions, and the $\mathrm{BN}$ nanotubes are crystallizes from this supersaturated solution as the temperature is decreased following a solid-liquid-solid mechanism. Thus, the nucleation and growth of BN nanotubes and other nanostructures is expected to takes place by a combination of VLS and SLS mechanisms.

\subsection{Surface and Internal Morphologies of $\mathrm{BN}$ Nanostructures}

Scanning electron microscopy (SEM) analysis was used to examine the surface morphology of $\mathrm{BN}$ nanostructures produced in the present work. Figure 6 shows a SEM mic- rograph of high-density $\mathrm{BN}$ nanostructures including nanotubes, nanoparticles and nanofibers etc. produced from a $50 \mathrm{~h}$ milled B powder followed by annealing at $1250^{\circ} \mathrm{C}$ under $\mathrm{NH}_{3}$. The micrograph shows that the nanotubes are grown inside the cluster suggesting that the powder-like cluster actually consists of large number of BN nanotubes as well as nanoparticles. The diameter of the $\mathrm{BN}$ tubes was around $20 \mathrm{~nm}-50 \mathrm{~nm}$ and length several microns.

$\mathrm{X}$-Ray dispersive analysis (EDS) was carried out to measure elemental $\mathrm{B}$, nitrogen, $\mathrm{Fe}$ and other elements. To increase the measurement accuracy, the powdered samples were pressed into pellets of diameter $6.00 \mathrm{~mm}$ with a smooth surface before the measurement. The EDS spectra (Figure 7) were collected from a large area of the pallet as well as from several places on each pellet and thus an average content of each element were obtained

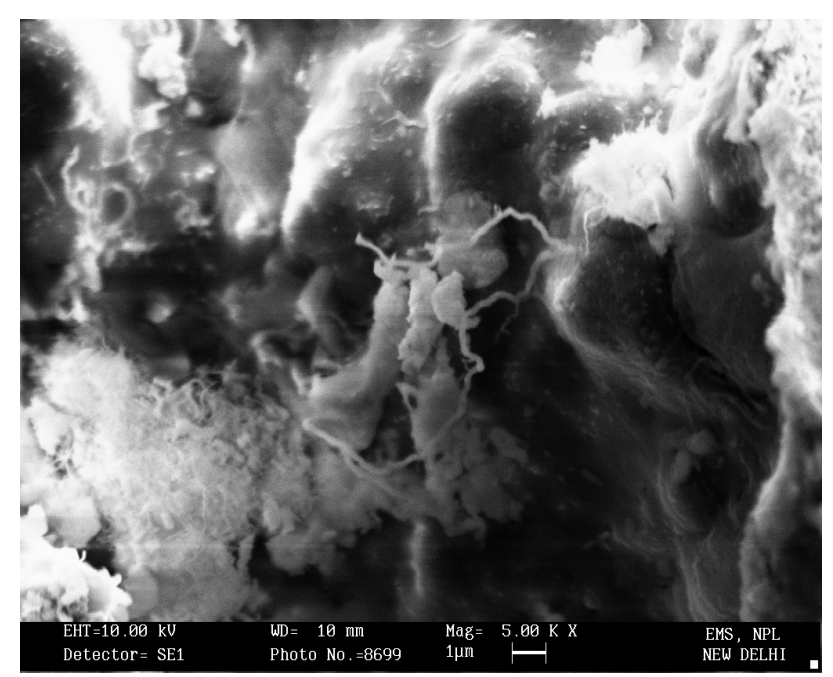

Figure 6. SEM micrograph of $\mathrm{BN}$ nanotubes produced from $B$ powder ball milled for $50 \mathrm{~h}$ in $\mathrm{NH}_{3}$ and annealed at $1250^{\circ} \mathrm{C}$ in $\mathrm{NH}_{3}$ for 6 hours. 
for comparison between different samples. The EDS analysis confirmed that the nanotube consists of elemental B and $\mathrm{N}$, as indicated by the pronounced $\mathrm{B}$ and $\mathrm{N}$ peaks shown in Figure 7.

The peaks of $\mathrm{O}$ and $\mathrm{Fe}$ are due to exposure to air and contamination during milling from steel balls and container. The peaks of $\mathrm{Cr}$ could not be seen in Figure 7. Fe nanoparticles act as a catalyst and enhance BN nanotube formation during the subsequent annealing. Therefore, high-energy ball milling creates a new disordered structure mixed with metal catalysts for subsequent $\mathrm{BN}$ nanotube growth. The peak of Au in the EDS spectra is mainly due to gold thin film deposited on the samples before SEM characterization study.

A detailed characterization employing HR-TEM equiped with EDS, delineated many useful information of BN nano-objects. Figures 8(a)-(e) shows HR-TEM images of

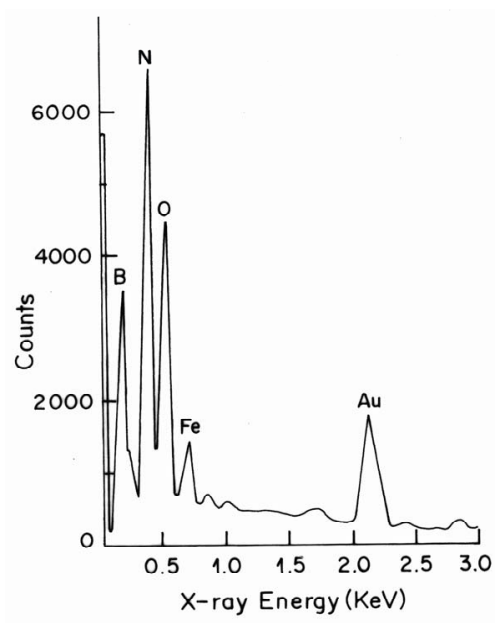

Figure 7. EDS spectra of $\mathrm{BN}$ nanotubes showing the presence of $B$ and $N$ and low levels of $O$ and $F e$.

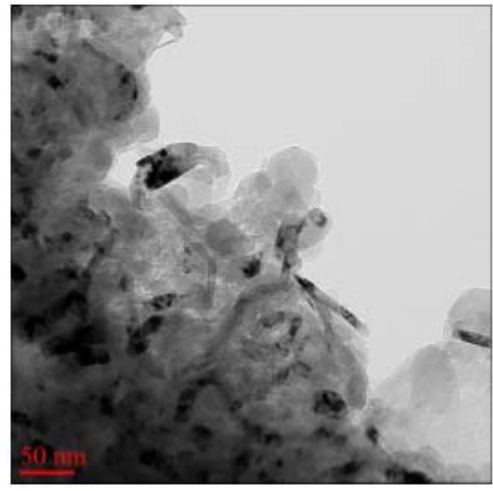

(a)

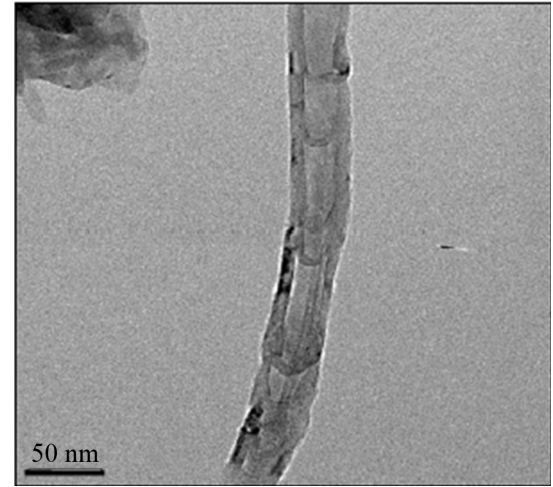

(b)

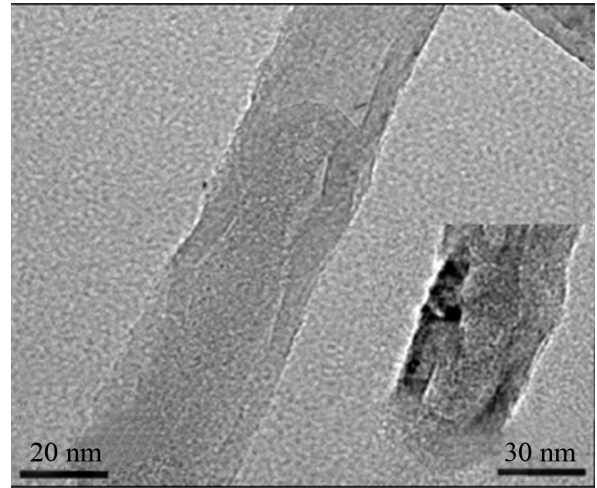

(c)

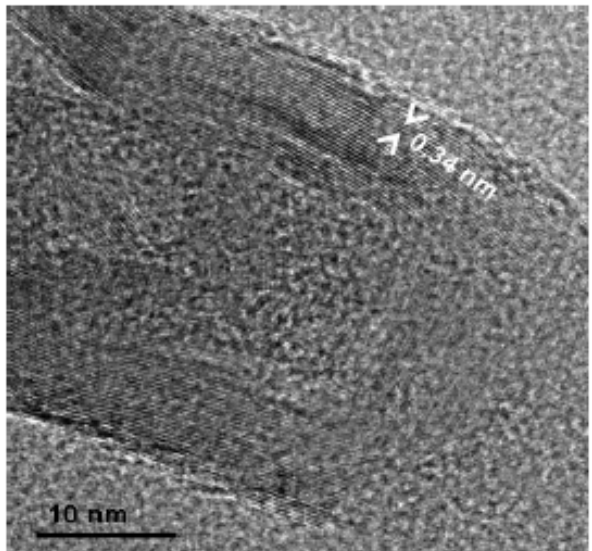

(d)

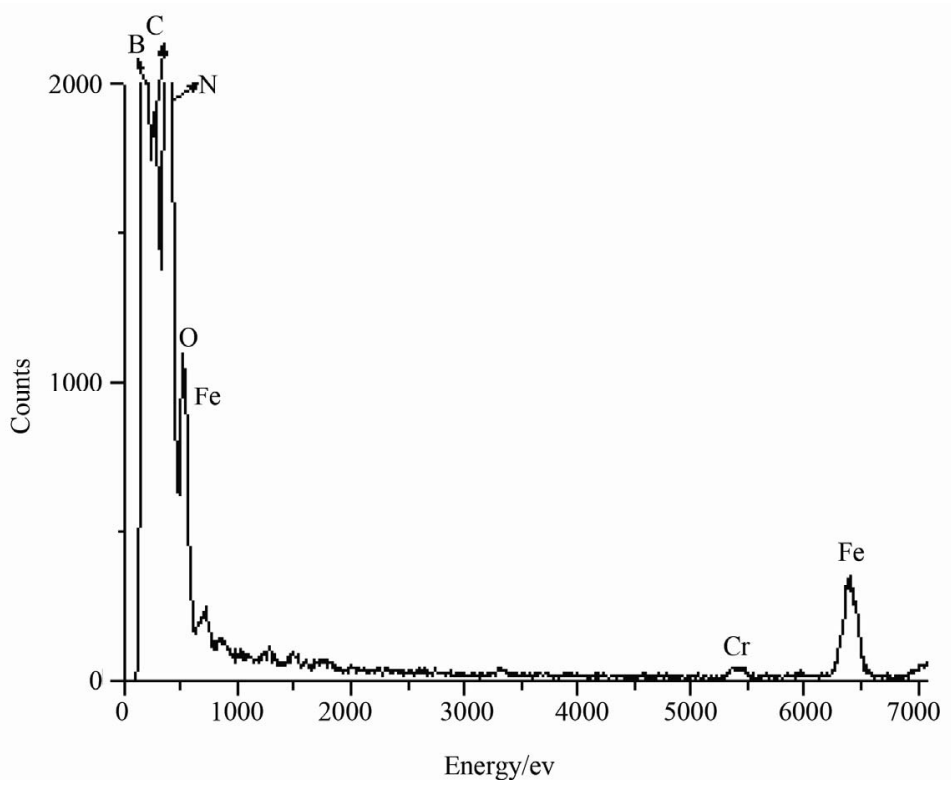

(e)

Figure 8. HR-TEM images of (a) BN nanostructures; (b) Bamboo-like BN nanotubes; (c) Enlarged view of nanotube, the inset shows a complete filling of a compartment; (d) Multi walled structure of a nanotube; and (e) EDS spectrum. 
BN nanostructures (nanotubes, nanofibers, nanoparticles etc) produced from $\mathrm{B}$ powder milled for $50 \mathrm{~h}$ and annealed at $1250^{\circ} \mathrm{C}$ in $\mathrm{NH}_{3}$ for $6 \mathrm{~h}$.

Figure 8(a) exhibits a conventional bright field electron micrograph revealing the presence of $\mathrm{BN}$ nanotubes of diameter 20 to $50 \mathrm{~nm}$. These nanotubes are aggregated with ultrafine-sized nanoparticles of size less than 100 nm. Figure 8(b) shows an individual BN nano- tube having bamboo-like morphology with different compartments $(\sim 50 \mathrm{~nm}-70 \mathrm{~nm})$. It has been understood that the compartments that could have formed by the expulsion of the catalyst or the detachment of tubular structure from the catalyst [29]. The molten catalyst is occasionally partially trapped inside the bamboo-like nanotubes as shown in Figure 8(a), and may be responsible for the formation of these nanostructures via an improved stress-induced sequential growth mechanism. The overall diameter of these nanotubes was found to be almost uniform throughout the length, and are different from spindle-like morphology observed by Huo et al. [30] from the nitridation of $\mathrm{Fe}-\mathrm{B}$ nanoparticles at $1100^{\circ} \mathrm{C}$ in the presence of a mixture of nitrogen and ammonia where the tube diameter was found to decrease along the growth direction, although the growth mechanism for the formation of these defective BN nanostructures was al- most similar and follow the stress-induced sequential growth mechanism.

Figure 8(c) represents an individual $\mathrm{BN}$ nanotube, examined at higher magnification. Fe nanoparticles were found to entrap between the walls of nanotubes as confirmed by EDS analysis. An inset in Figure 8(c) further elucidated a complete filling of a compartment by Fe. Figure 8(d) shows the enlarged view of the bamboo-like $\mathrm{BN}$ nanotube, revealing the structure of the tip of the tube in detail. The image shows that the nanotube is well crystallized with the multiwalled structure on both sides of tube with lattice spacing between two neighboring fringes of $\sim 0.34 \mathrm{~nm}$, corresponding to $\mathrm{d}_{0002}$ spacing in bulk hexagonal BN $(0.333 \mathrm{~nm})$ [31]. The tip of the corresponding nanotube was found to be rectangular in shape (Figure 8(d)). Figure 8(e) represents the EDS analysis of the tube nanostructures (as observed in Figure 8(c) such as BN nanotubes filled with catalyst nanoparticles, BN nanofibers, catalyst nanoparticles etc. The spectrum shows some additional peaks of $\mathrm{Fe}, \mathrm{Cr}$ etc in addition to the peaks observed for $\mathrm{B}, \mathrm{N}, \mathrm{C}$ and $\mathrm{O}$. The weak signal at $\sim 530 \mathrm{eV}$ is due to the oxygen adsorption during sample transfer through air.

Figures 9(a) and (b) represents the transmission electron micrographs of surface modified BN nanotubes produced in the present work. Figure 9(b) shows the enlarge view of the one of the nanotubes as displayed in Figure 9(a). Figure 9(c) represents the corresponding EDS

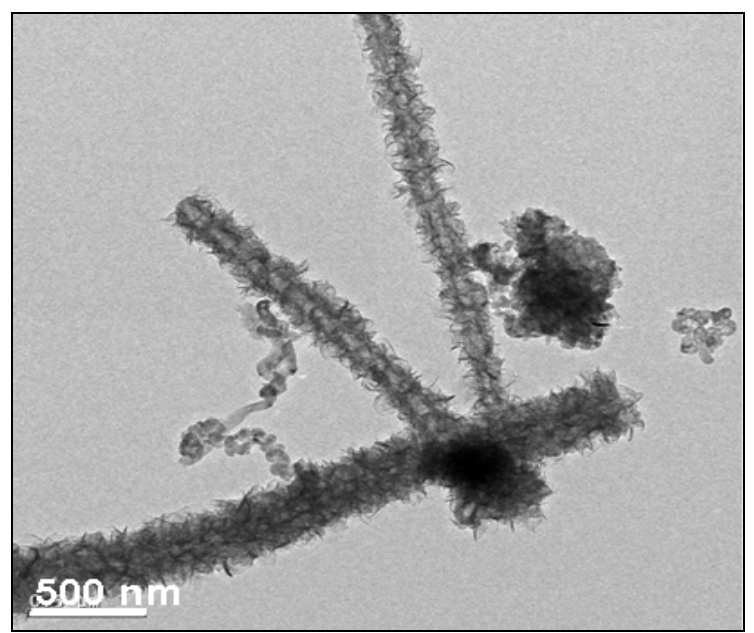

(a)

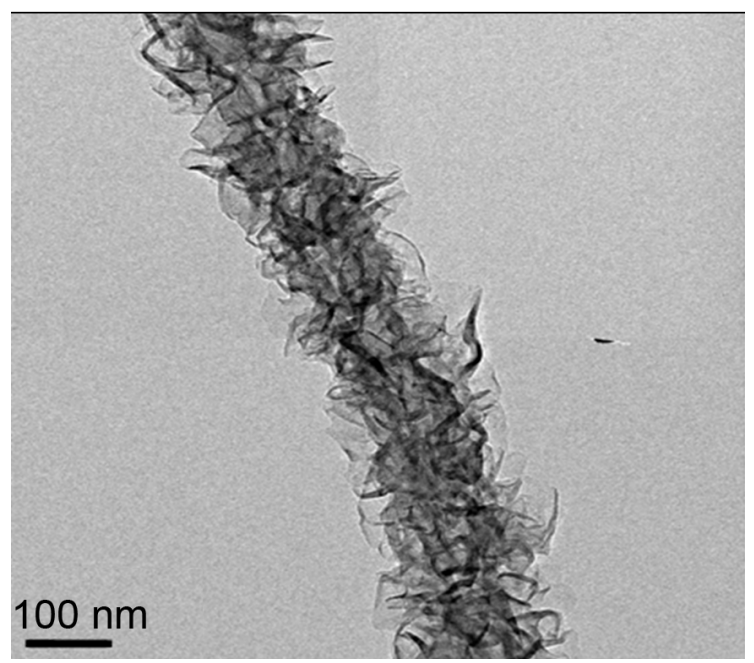

(b)

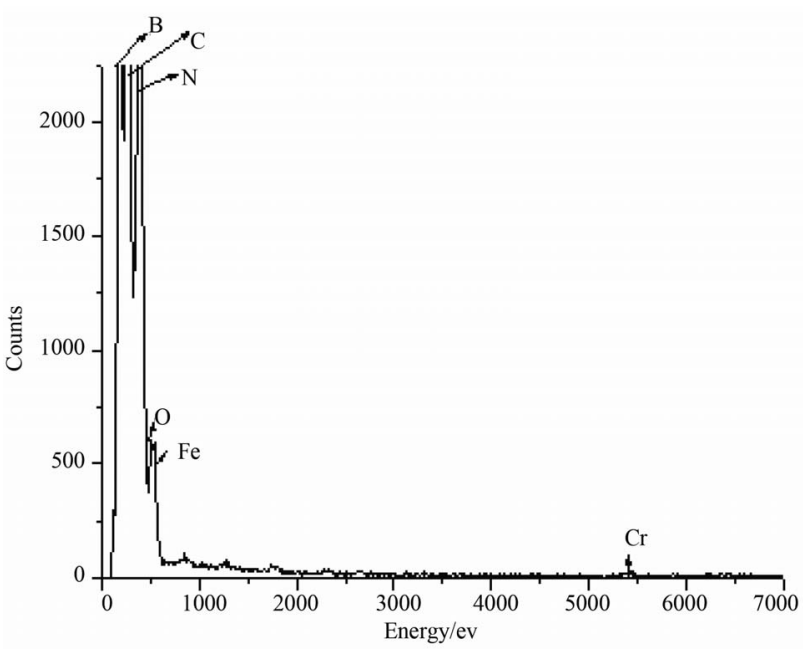

(c)

Figure 9. HR-TEM image of (a) Surface modified BN nanotubes; (b) Enlarged view; and (c) EDS spectrum of surface modified BN nanotubes. 
spectrum of the surface modified BN nanotubes. These nanostructures consist of nanotubes, nanofibers and to some extent nanosheets exhibiting large surface area. The nanofibers attached to the surface of the tubes are different from tubes in that they do not have any hollow cores and thus, results an extraordinary increased surface area. The Brunauer, Emmett and Teller (BET) measurements have shown that $\mathrm{BN}$ nanofibers have a specific surface area $\sim 260 \mathrm{~m}^{2} / \mathrm{g}$ in comparison with $\sim 210$ and $\sim 150 \mathrm{~m}^{2} / \mathrm{g}$ in bamboo-like nanotubes and in multi walled nanotubes, respectively. The nanofibers as shown in Figure 9(b) usually exhibited a defective structure and rough surface. The surface feature is somewhat to that of bamboo-like nanotubes. However, for BN nanofibers as shown in Figures 9(a) and (b) all the BN layers may be considered to be open on the external surface. This feature increases the surface area of the material and also decreases the energy barrier for trapping $\mathrm{H}_{2}$ due to the existence of "wedge" channels onto the exterior surface. The BN layers were separated by $0.34 \mathrm{~nm}$ as shown in Figure 8(d), which is slightly larger than the kinetic diameter, 0.29 $\mathrm{nm}$, of $\mathrm{H}_{2}$ molecules. Under high pressures, the open-e nded BN layers may be assumed to be major channels for encapsulating $\mathrm{H}_{2}$; a mechanism similar to the pathways proposed for $\mathrm{H}_{2}$ storage in $\mathrm{C}$ nanofibers [32]. Unlike CNTs, whose non-polar C-C bonds form a uniform and smooth sidewall structures, boron nitride nanotubes contain hetropolar B-N bonding [33] with ionic character. Here it is mentioned that such surface modified or collapsed BN nanotubes have also been synthesized earlier by Terao et al. [24] using carbon-free CVD method using a mixture of $\mathrm{B}, \mathrm{MgO}, \mathrm{SnO}$ and $\mathrm{ZnS}$ powders and heating them at $1450^{\circ} \mathrm{C}$ in the presence of ammonia for 2 $\mathrm{h}$, the overall yield of these nanotubes obtained was still very low. However, in the present process, we have been able to achieve a high yield of surface modified $\mathrm{BN}$ nanotubes for the first time using mechanothermal process. In our subsequent studies, we are in the process of optimizing synthesis conditions to obtain single phase of these nanotubes in throughout the product.

\subsection{Influence of Luminescence Due to Different BN Nanostructures}

In addition to the studies of hydrogen storage capacity of $\mathrm{BN}$ nanostructures as investigated by several investigators [8-11], the BN nanostructures were also analyzed employing photoluminescence (PL) spectroscopy in the present work. Figure 10 shows the PL spectra of one typical sample of BN nanotubes produced in the present study. The spectra has one main emission peak centered around $340 \mathrm{~nm}$, and two small emission peaks around 515 and $525 \mathrm{~nm}$ respectively which are the characteris-

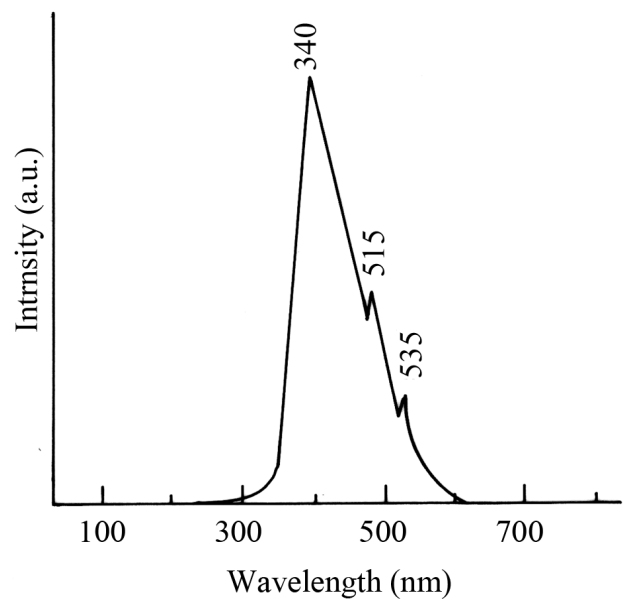

Figure 10. PL spectrum of BN nanotubes.

tics PL emissions associated with hexagonal boron nitride structure [34]. The emission peaks at around 515 and $535 \mathrm{~nm}$ are presumably due to small band gap of BN nanotubes produced in this work. It has been shown by $\mathrm{Yu}$ et al. [35] that the band gap of BN nanotubes becomes smaller when the tube diameter decreases. It is likely that at lower milling time used in the present work, nanotubes with small diameter (band gap $2.32 \mathrm{eV}$ ) predominate. The small diameter of the nanotubes produced in the present study has also been confirmed by SEM and HRTEM results shown in Figures 6 and 8 respectively.

\section{Conclusions}

The present method demonstrates the synthesis of surface modified BN nanotubes coexisting with conventional nanotubes, from the mechanical alloying of elemental boron powder in the presence of a controlled atmosphere followed by annealing in $\mathrm{NH}_{3}$ for $6 \mathrm{~h}$. These nanotubes have been found to exhibit with large surface area than the well crystalline $\mathrm{BN}$ nanotubes and could have many applications including the hydrogen storage. Although these surface modified $\mathrm{BN}$ nanotubes could also be produced from CVD in- volving various chemical systems, the yield produced using these methods is not satisfactory. However, using the present method one can synthesize a very high yield of surface modified BN nanotubes. Photoluminescence measurements led to possible band gap engineering of BN nanostructures based on the morphology and diameter of the product phase.

\section{Acknowledgements}

The authors are grateful to the Director, National Physical Laboratory, New Delhi for his permission to publish the results reported in the present work. Sincere thanks are due to Mr. K.N. Sood and Ms Arpita Vajpayee for 
their help in SEM and XRD characterization of BN nanotubes produced in this work.

\section{References}

[1] C. H. Lee, J. Wang, V. K. Kayatsha, J. Y. Huang and Y. K. Yap, "Effective Growth of Boron Nitride Nanotubes by Thermal Chemical Vapor Deposition," Nanotechnology, Vol. 19, No. 45, 2008, pp. 455605. doi:10.1088/0957-4484/19/45/455605

[2] Y. Chen, J. Zou, S. J. Campbell and G. L. Caer, "Boron Nitride Nanotubes: Pronounced Resistance to Oxidation," Applied Physics Letters, Vol. 84, No. 13, 2004, pp. 24302433. doi:10.1063/1.1667278

[3] C. W. Chang, W.-Q. Han and A. Zettl, "Thermal Conductivity of B-C-N and BN Nanotubes," Applied Physics Letters, Vol. 86, No. 17, 2005, pp. 173102-173104. doi:10.1063/1.1914963

[4] J. Ravichandran, A. G. Manoj, J. Liu, I. Manna and D. L. Carrol, "A Novel Polymer Nanotube Composite for Photovoltaic Packaging Applications," Nanotechnology, Vol. 19 , No. 8, 2008, p. 085712. doi:10.1088/0957-4484/19/8/085712

[5] N. P. Bansal, J. B. Hurst and S. R. Choi, "Boron Nitride Nanotubes-Reinforced Glass Composites" Journal of the American Ceramic Society, Vol. 89, No. 1, 2006, pp. 388-389. doi:10.1111/j.1551-2916.2005.00701.x

[6] S. S. Han and H. M. Lee, "Adsorption Properties of Hydrogen on $(10,0)$ Single-Walled Carbon Nanotube through Density Functional Theory," Carbon, Vol. 42, No. 11, 2004, pp. 2169-2177. doi:10.1016/i.carbon.2004.04.025

[7] J. Lawrence and G. Xu, "High Pressure Saturation of Hydrogen Stored by Single-Wall Carbon Nanotubes," Applied Physics Letters, Vol. 84, No. 6, 2004, pp. 918-920. doi:10.1063/1.1646728

[8] S. H. Lim, J. Luo, W. Li and J. Lin, "Synthesis of Boron Nitride Nanotubes and Its Hydrogen Uptake," Catalysis Today, Vo. 120, No. 3-4, 2007, pp. 346-350.

doi:10.1016/j.cattod.2006.09.016

[9] R. Ma, Y. Bnado, T. Sato, D. Golberg, H. Zhu, C. Xu and D. Wu, "Synthesis of Boron Nitride Nanofibers and Measurement of Their Hydrogen Uptake Capacity," Applied Physics Letters, Vol. 81, No. 27, 2002, pp. 5225-5257. doi:10.1063/1.1534415

[10] Z. Zhou, J. Zhao, Z. Chen, X. Gao, T. Yan, B. Wen, P. Van and R. Schlayer, "Comparative Study of Hydrogen Adsorption on Carbon and BN Nanotubes," Journal of Physical Chemistry B, Vol. 110, No. 27, 2006, pp. 1336313369. doi: $10.1021 / \mathrm{jp} 0622740$

[11] C. C. Tang, Y. Bando, X. Ding, S. Qi and D. Golberg, "Catalyzed Collapse and Enhanced Hydrogen Storage of BN Nanotubes," Journal of the American Chemical Society, Vol. 124, No. 49, 2002, pp. 14550-14551. doi:10.1021/ja028051e

[12] N. G. Chopra, R. J. Luyken, K. Cherrey, V. H. Crespi, M. L. Cohen, S. G. Louie and A. Zettl, "Boron Nitride Nano- tubes," Science, Vol. 269, No. 5226, 1995, pp. 966-967. doi:10.1126/science.269.5226.966

[13] D. Golberg, Y. Bando, M. Eremets, K .Takemura, K. Kurashima and H. Yusa, "Nanotubes in Boron Nitride Laser Heated at High Pressure," Applied Physics Letters, Vol. 69, No. 14, 1996, pp. 2045-2047.

doi:10.1063/1.116874

[14] D. Golberg, W. Han, Y. Bando, L. Bourgeois, K. Kurashima and T. Sato, "Fine Structure of Born Nitride Nanotubes Produced from Carbon Nanotubes by a Substitution Reaction," Journal of Applied Physics, Vol. 86, No. 4, 1999, pp. 2364-2366. doi:10.1063/1.371058

[15] C. C. Tang, Y. Bando, T. Sato and K. Kurashima, "A Novel Precursor for the Synthesis of Pure Boron Nitride Nanotubes," Chemical Communications, No. 12, 2002, pp 1290-1291. doi:10.1039/B202177C

[16] Y. Chen, J. F. Gerald, J. S. Williams and S. Bulcock, "Synthesis of Boron Nitride Nanotubes at Low Temperatures Using Reactive Ball Milling," Chemical Physics Letters, Vol. 299, No. 3-4, 1999, pp. 260-264. doi:10.1016/S0009-2614(98)01252-4

[17] Y. Chen, L. T. Chadderton, J. F. Gerald, J. S. Williams, "A Solid-State Process for the Formation Boron Nitride Nanotubes," Applied Physics Letters, Vol. 74, No. 20, 1999, pp. 2960-2962. doi:10.1063/1.123979

[18] Y. Chen, J. F. Gerald, J. S. Williams and P. Willis, "Mechanochemical Synthesis of Boron Nitride Nanotubes," Journal of Metastable and Nanocrystalline Materials, Vol. 2-6, 1999, pp. 173-187. doi:10.4028/www.scientific.net/JMNM.2-6.173

[19] Y. Chen, M. Conway J. S. Williams and J. Zou, “ LargeQuantity Production of High-Yield Boron Nitride Nanotubes," Journal of Materials Research, Vol. 17, No. 8, 2002, pp. 1896-1899. doi:10.1557/JMR.2002.0281

[20] S. K. Singhal, A. K. Srivastva, R. P. Pant, S. K. Halder, B. P. Singh and A. K. Gupta, "Synthesis of Boron Nitride Nanotubes Employing Mechanothermal Process and Its Characterization," Journal of Materials Science, Vol. 43, No. 15,2008 , pp. 5243-5250. doi:10.1007/s10853-008-2770-3

[21] J. F. Gerald, Y. Chen and M. J. Conway, "Nanotube Growth during Annealing of Mechanically Milled Boron," Applied Physics A, Vol. 76, No. 1, 2003, pp.107-110. doi:10.1007/s00339-002-1441-5

[22] S. Y. Bae, H. W. Seo, J. Park, Y. S. Choi, J. C. Park and S. Y. Lee, "Boron Nitride Nanotubes Synthesized in The Temperature Range $1000^{\circ} \mathrm{C}-1200^{\circ} \mathrm{C}$," Chemical Physics Letters, Vol. 374, No. 5-6, 2003, pp. 534-541. doi:10.1016/S0009-2614(03)00745-0

[23] F. Q. Ji, C. B. Cao, H. Xu and Z. G. Yang, "Mechanosynthesis of Boron Nitride Nanotubes," Chinese Journal of Chemical Engineering, Vol. 14, No. 3, 2006, pp. 389393. doi:10.1016/S1004-9541(06)60088-8

[24] T. Terao, Y. Bando, M. Mitome, K. Kurashima, C. Y. Zhi, C. C. Tang and D. Golberg, "Effective Synthesis of Surface-Modified Boron Nitride Nanotubes and Related Nanostructures and Their Hydrogen Uptake," Physica E, Vol. 
40, No. 7, 2008, pp. 2551-2555. doi:10.1016/j.physe.2007.10.014.

[25] C. Y. Zhi, Y. Bando, C. C. Tang and D. Golberg, "Effective Precursor for High Yield Synthesis of Pure BN Nanotubes," Solid State Communications, Vol. 135, No. 1-2, 2005, pp. 67-70. doi:10.1016/j.physe.2007.10.014.

[26] J. Yu, Y. Chen, R. G. Elliman and M. Petravic," Isotopically Enriched 10BN Nanotubes," Advanced Materials, Vol. 18, No. 16, 2006, pp. 2157-2160. doi:10.1002/adma.200600231

[27] G. J. Tibbetts, "Why Are Carbon Filaments Tubular," Journal of Crystal Growth, Vol. 66, No. 3, 1984, pp. 632-638. doi:10.1016/0022-0248(84)90163-5

[28] L. T. Chadderton and Y. Chen, "Nanotube Growth by Surface Diffusion," Physics Letters A, Vol. 263, No. 4-6, 1999, pp. 401-405. doi:10.1016/S0375-9601(99)00731-8

[29] L. T. Chadderton and Y. Chen, "A Model for the Growth Bamboo and Skeletal Nanotubes: Catalytic Capillarity," Journal of Crystal Growth, Vol. 240, No. 1-2, 2002, pp. 164-169. doi:10.1016/S0022-0248(02)00855-2

[30] H. F. Huo, Z. Hu, J. J. Fu, H. Xu, X. Z. Wang, Y. Chen and Y. N. Lu, "Microstructure and Growth Model of Period Spindle-Unit BN Nanotubes by Nitriding Fe-B Nanoparticles with Nitrogen/Ammonia Mixture," Journal of
Physical Chemistry B, Vol. 107, No. 41, 2003, pp. 11316 11320. doi:10.1021/jp035375w

[31] K. F. Hou, Z. Hu, F. Chen, J. J. Fu, Y. Chen, B. H. Liu, J. Ding, Z. L. Dong and T. White, "Synthesis of Boron Nitride Nanowires," Applied Physics Letters, Vol. 80, No. 19, 2002, pp. 3611-3613. doi:10.1063/1.1479213

[32] A. Chambers, C. Park, R. T. K. Baker and N. M. Rodriguez, "Hydrogen storage in Graphite Nanofibers," Journal of Physical Chemistry B, Vol. 102, No. 22, 1998, pp. 4253-4256. doi:10.1021/jp9801141.

[33] S. Jhi and Y. Kwon, "Hydrogen Adsorption on Boron Nitride Nanotubes: A Path to Room-Temperature Hydrogen Storage," Physical Review B, Vol. 69, No. 24, 2004, p. 245407. doi:10.1103/Phys Rev B.69.245407

[34] J. Yu, Y. Chen, R. Wuhrer, Z. Liu and S. P. Ranger, "Insitu Formation of BN Nanotubes during Nitriding Reactions," Chemistry of Materials, Vol. 17, No. 20, 2005, pp. 5172-5176. doi:10.1021/cm050966f

[35] J. Yu, D. Yu, Y. Chen, H. Chen, M. Y. Lin, B. M. Cheng, J. Li and W. Duan, "Narrowed Bandgaps and Stronger Excitonic Effects from Small Boron Nitride Nanotubes," Chemical Physics Letters, Vol. 476, No. 4-6, 2009, pp. 240-243. doi:10.1016/j.cplett.2009.06.012 